eISSN 2444-7986

DOI: https://doi.org/10.14201/orl.16651

Caso clínico

\title{
SORDERA NEUROSENSORIAL POR MUTACIÓN DEL GEN MYH14. DESCRIPCIÓN DE UN CASO
}

\section{Sensorineural hearing loss caused by MYH14 gene mutation. A case report}

\author{
Pedro CARNEIRO-SOUSA; Inês GAMBÔA; Delfim DUARTE; Nuno TRIGUEIROS-CUNHA
}

Servicio de Otorrinolaringología. Hospital Pedro Hispano - Unidade Local de de Saúde de Matosinhos. Matosinhos. Portugal.

Correspondencia:pedrojmcs@gmail.com

Fecha de recepción: 14 de junio de 2017

Fecha de aceptación: 13 de julio de 2017

Fecha de publicación: 16 de julio de 2017

Fecha de publicación del fascículo: 1 de marzo de 2018

Conflicto de intereses: Los autores declaran no tener conflictos de intereses

Imágenes: Los autores declaran haber obtenido las imágenes con el permiso de los pacientes

Política de derechos y autoarchivo: se permite el autoarchivo de la versión post-print (SHERPA/RoMEO)

Licencia CC BY-NC-ND. Licencia Creative Commons Atribución-NoComercial-SinDerivar 4.0 Internacional

Universidad de Salamanca. Su comercialización está sujeta al permiso del editor

RESUMEN

PALABRAS CLAVE

SUMMARY

KEYWORDS
Introducción y objetivo: Las causas hereditarias son responsables de la mitad de los casos de hipoacusia neurosensorial en jóvenes. La mutación del gen MYH14 es autosómica dominante. Descripción: Paciente varón de 33 años con hipoacusia neurosensorial bilateral moderada a severa. El estudio genético mostró mutación del gen MYH14. Discusión: Es un caso de sordera neurosensorial poslingual, compatible con una herencia autosómica dominante. La mutación del gen MYH14 puede aumentar la susceptibilidad para el trauma acústico, justificando la aparición tardía de la sordera. Conclusiones: La mutación del gen MYH14 es, probablemente, una causa de sordera. El estudio genético tiene una crecente importancia.

sordera neurosensorial; gen MYH14; miosina; genética; mutación

Introduction and objective: Hereditary causes are responsible for half of cases of sensorineural hearing loss in young people Mutation of the MYH14 gene is autosomal dominant. Description: A 33 years-old male patient with moderate to severe bilateral sensorineural hearing loss. Genetic study revealed MYH14 gene mutation. Discussion: This is a case of post-lingual sensorineural deafness, compatible with autosomal dominant inheritance. MYH14 mutation seems to increase susceptibility to acoustic trauma, which may justify the late onset of hearing loss. Conclusions: MYH14 mutation is, probably, a cause for hearing loss. Genetic study has, therefore, a growing importance.

sensorineural hearing loss; MYH14 gene; myosin; genetics; mutation 


\section{INTRODUCCIÓN}

La hipoacusia neurosensorial en enfermos jóvenes menores de 35 años es un desafío diagnóstico. En primer lugar, es importante hacer un examen de imagen (tomografía computarizada $-\mathrm{TC}-\mathrm{o}$ resonancia magnética $-\mathrm{RM}-$ ) para excluir condiciones más frecuentes como traumatismo en el hueso temporal o enfermedad desmielinizante [1]. También es necesario, través de historia clínica, saber se hubo exposición a aminoglucósidos o infección perinatal por el grupo TORCHES (toxoplasmosis, rubeola, citomegalovirus, herpes simple, sífilis), que puede tener un efecto tardío en audición [2].

Las causas hereditarias son responsables en cerca del $50 \%$ de los casos de sordera en enfermos jóvenes. Aproximadamente el $70 \%$ de estos casos son no sindrómicos, el $15 \%$ a $20 \%$ originados por mutaciones autosómicas dominantes [3].

El gen MYH14 codifica una de las cadenas pesadas de la isoforma no muscular de la miosina tipo II, que es expresada en grandes cantidades en la cóclea [4]. Este gen se encuentra localizado en una región asociada con sordera autosómica dominante (DFNA4: autosomal dominant hearing impairment 4) en familias independientes [3, 4].

\section{DESCRIPCIÓN}

Paciente varón de 33 años que consultó en otorrinolaringología porque fue sometido a septoplastia. Refería hipoacusia bilateral desde los 8 años. La otoscopia y la acumetría eran normales, sin síntomas ni signos de vértigo y sin historia de complicaciones perinatales. La audiometría de 10 años antes mostraba una sordera neurosensorial moderada a severa en ambos oídos (Figura 1). En una nueva audiometría se observó una ligera agravación de la hipoacusia (Figura 2). Los potenciales evocados auditivos tenían valores normales de amplitud y latencia de las ondas, la RM cerebral, el electrocardiograma (para exclusión del síndrome de Jervell y Lange-Nielsen) y la inmunología (anticuerpos contra el musculo liso, anti-ADN de doble cadena, anticuerpos antinucleares, anticocleares, anticitoplasma de neutrófilos -ANCA's- y factor reumatoide) no mostraron alteraciones. Se realizó una prueba terapéutica con prednisolona oral en dosis de $40 \mathrm{mg} /$ día durante 10 días, pero la audiometría fue idéntica.
Finalmente, el estudio genético realizado en el Centro de Genética Preditiva e Preventiva (Oporto) identificó una mutación heterocigótica del gen MYH14 (sustitución c.181G>C en exón 5 , resultando la sustitución de un ácido glutámico por una glutamina). Se pidió la secuenciación del exoma completo de un panel de 103 genes asociados a sordera no sindrómica. El paciente fue referenciado para consulta en el mismo centro genético junto con sus padres, para completar el estudio.
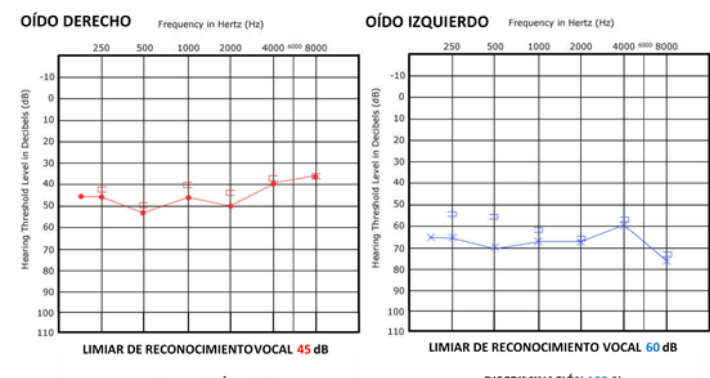

DISCRIMINACIÓN $100 \%$

DISCRIMINACIÓN $100 \%$

Figura 1. Primera audiometría.



DISCRIMINACIÓN $100 \%$

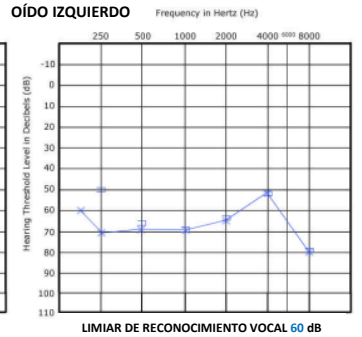

DISCRIMINACIÓN $100 \%$
Figura 2. Segunda audiometría

\section{DISCUSIÓN}

En este caso, la hipoacusia en edad poslingual son compatibles con una herencia autosómica dominante. La ausencia de historia familiar de sordera precoz es un argumento en contra.

La mutación del gen MYH14 en enfermos sordos fue primeramente identificada en familias en el sur de China [3].

Es interesante que, tal como en otros países europeos (Italia y Bélgica) [4], la mutación de este caso en Portugal ha sido también, una sustitución. Sin embargo, es una sustitución diferente de las detalladas en otros artículos [5]. A pesar de estar expresado en otros órganos, como el cerebro, los nervios periféricos, el 
músculo esquelético y el intestino [6], la mutación del gen MYH14 en este paciente, no ha inducido otras manifestaciones aparte de la sordera.

El gen MYH14 es responsable de una cadena de miosina. Las miosinas son proteínas motoras con diversas funciones, incluyendo la regulación de citocinesis y de la motilidad celular. Un estudio en ratas ha comprobado una asociación con la susceptibilidad a la lesión provocada por el trauma acústico [7]. Si esto se confirma en humanos, este mecanismo puede justificar la hipótesis de la mutación del gen MYH14 como causa de hipoacusia poslingual.

\section{CONCLUSIONES}

Este caso clínico puede justificar el papel del gen MYH14 como posible causante de la sordera en enfermos con DFNA4. En este paciente, hemos identificado una nueva mutación del gen MYH14, hasta ahora no descrita en la literatura, que es la causa más probable de la sordera.

Es, por lo tanto, muy importante el estudio genético para identificar la etiología de casos de hipoacusia neurosensorial en pacientes sin otra causa probable. Hoy por hoy, cada vez más genes y mutaciones son identificados y relacionados con la sordera hereditaria.

\section{AGRADECIMIENTOS}

Los autores agradecen a el Centro de Genética Preditiva e Preventiva por la rápida e inmediata realización y comunicación de los resultados del estudio genético de este caso.

\section{BIBLIOGRAFÍA}

1. Mafong DD, Shin EJ, Lalwani AK. Use of laboratory evaluation and radiologic imaging in the diagnostic evaluation of children with sensorineural hearing loss. Laryngoscope. 2002;112:1-7.

2. De Leenheer EMR, Janssens $S$, Padalko E, Loose D, Leroy BP, Dhooge IJ.. Etiological diagnosis in the hearing impaired newbord: Proposal of a flow chart. Int J Pediatr Otorhinolaryngol. 2011;75:27-32.
3. Zong L, Lu C, Zhao Y, Li Q, Han D, Yang $W$, et al. Clue to a new deafness gene: a large Chinese nonsyndromic hearing loss family linked to DFNA4. J Genet Genomics. 2012; 39:653-7.

4. Donaudy $F$, Snoeckx $R$, Pfister $M$, Zenner HP, Blin N, Di Stazio M, et al. Nonmuscle myosin heavy-chain gene MYH14 is expressed in cochlea and mutated in patients affected by autosomal dominant hearing impairment (DFNA4). Am J Hum Genet. 2004;74:770-6.

5. Qing J, Yan D, Zhou Y, Liu Q, Wu W, Xiao $Z$, et al. Whole-exome sequencing to decipher the genetic heterogeneity of hearing loss in a Chinese family with deaf by deaf mating. PLoS One. 2014;9:e109178.

6. Choi BO, Kang SH, Hyun YS, Kanwal S, Park SW, Koo H, et al. A complex phenotype of peripheral neuropathy, myopathy, hoarseness, and hearing loss is linked to an autosomal dominant mutation in MYH14. Hum Mutat. 2011;32:669-77.

7. Fu X, Zhang L, Jin $Y$, Sun $X$, Zhang A, Wen Z, et al. Loss of Myh14 Increases Susceptibility to Noise-Induced Hearing Loss in CBA/CaJ Mice. Neural Plast. 2016; 2016:6720420. 